\title{
GIANT PLEXIFORM NEUROFIBROMA OF LEFT GLUTEAL AND THIGH REGION: A CASE REPORT
}

\author{
P. Ravi Kumar Reddy ${ }^{1}$, Rajashekar S. B2 ${ }^{2}$ Somashekhar Samagandi ${ }^{3}$
}

\section{HOW TO CITE THIS ARTICLE:}

P. Ravi Kumar Reddy, Rajashekar S. B, Somashekhar Samagandi. "Giant Plexiform Neurofibroma of Left Gluteal and Thigh Region: A Case Report". Journal of Evolution of Medical and Dental Sciences 2015; Vol.4, Issue 16, February 23; Page: 2813-2817, DOI:10.14260/jemds/2015/402

\begin{abstract}
Plexiform neurofibromas are benign tumors arising from visceral or subcutaneous peripheral nerves, which are usually associated with neurofibromatosis type 1. Giant neurofibromas are a surgical challenge because of their vascularity and extensive infiltration and require preoperative and postoperative management strategies. This case report describes a 30 year old female with a giant plexiform neurofibroma of the left gluteal and thigh region $(27 \mathrm{~kg})$ in association with neurofibromatosis which was resected successfully.
\end{abstract}

KEYWORDS: Plexiform neurofibroma, gluteal and thigh region, neurofibromatosis.

INTRODUCTION:Neurofibromatosis type 1 (NF1) is a genetic syndrome which is autosomal dominant caused by mutations in genes encoding for neurofibromin ${ }^{1}$.NF1 is one of the most common human genetic diseases. ${ }^{1}$ Incidence estimated to be between 1 and 3000-4000 and equally affect both sexes. $^{2}$ According to Stedman's Medical Dictionary, plexiform neurofibroma (PN) is a type of neurofibroma representing an anomaly rather than a true neoplasm in which the proliferation of all elements of the nerve occur from the nerve sheath thereby resulting in an irregularly thickened, distorted tortuous structure ${ }^{3}$. Managing of patient with PN aims at relieving symptoms and surgery is probably the only therapy. These giant tumors are difficult to remove completely and tend to regrow 4 . Surgical treatment decisions and frequency of follow up should be made judiciously and individualized for each patient ${ }^{5}$. Here we present a case of giant plexiform neurofibroma of left gluteal and thigh region which is surgically resected successfully.

CASE REPORT:A 30 year old female presented at surgical outpatient complaining of left gluteal and thigh mass of 3 years duration. The mass is painless and progressively increased to present size gradually. There was no associated limitation of movement though she felt discomfort and difficulty and heaviness while walking and interefering with some routine activities. Mass surface became ulcerated since 6 months. There is history of weight loss but she had been in satisfactory health. She had no significant past medical history nor family history. There was also no history of neurofibromatosis in any sibling.

Examination showed a healthy looking female with no visual or auditory impairment, subcutaneous nodules are present all over the body, no café-au-lait spots or axillary/groin freckling. She had a large, firm, amorphous, fluctuant, soft tissue mass measuring 70 x 40 x30 with the base extending from left gluteal region to posterolateral aspect to anterior aspect of left thigh with two overhanging one from anteromedial aspect and another from posterolateral aspect, and with multiple dependant ulcers over the surface of the tumor. 


\section{CASE REPORT}

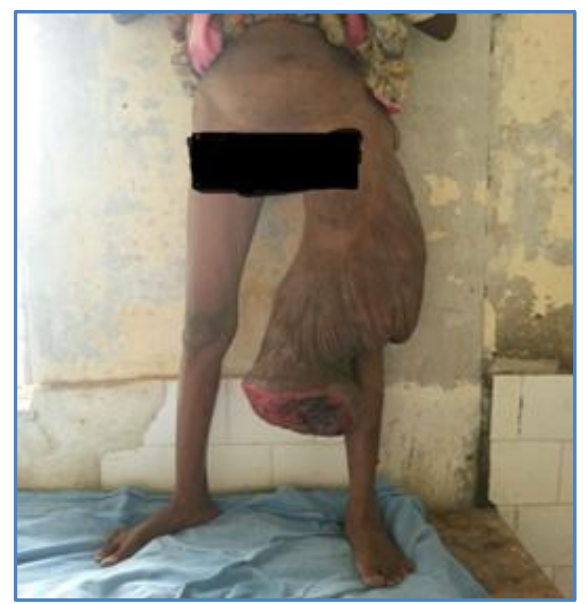

Fig. 1: Anterior aspect of tumor

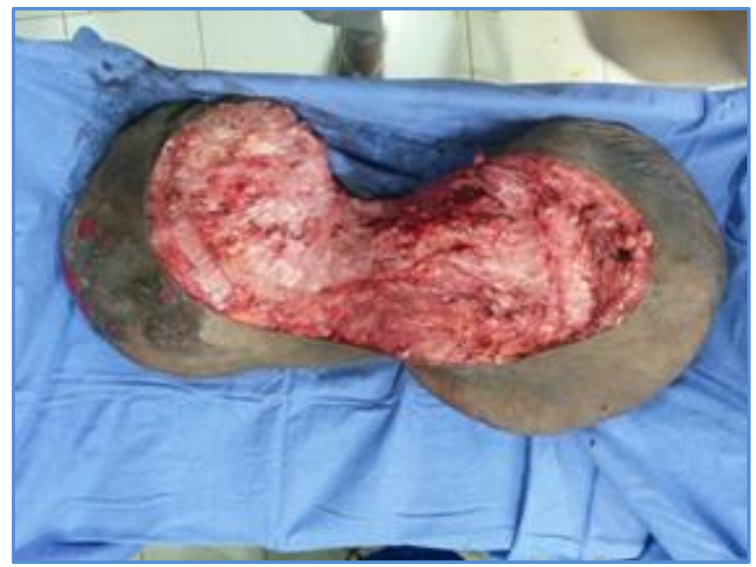

Fig. 3: Tumor removed

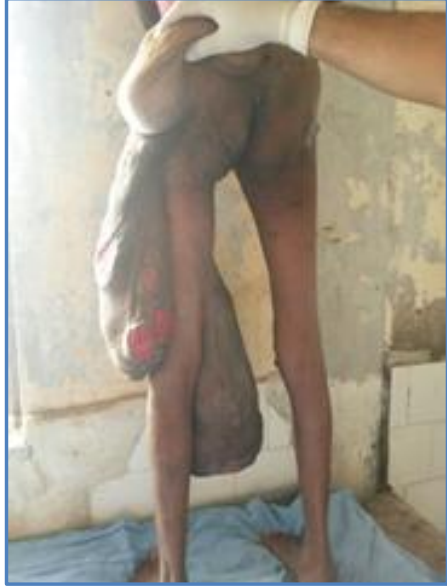

Fig. 2: Posterior aspect of the tumor

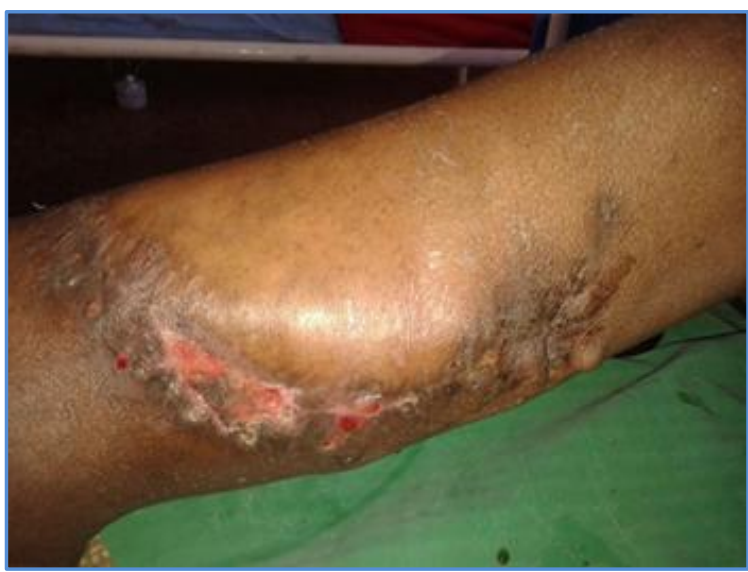

Fig. 4: Healed primary closure

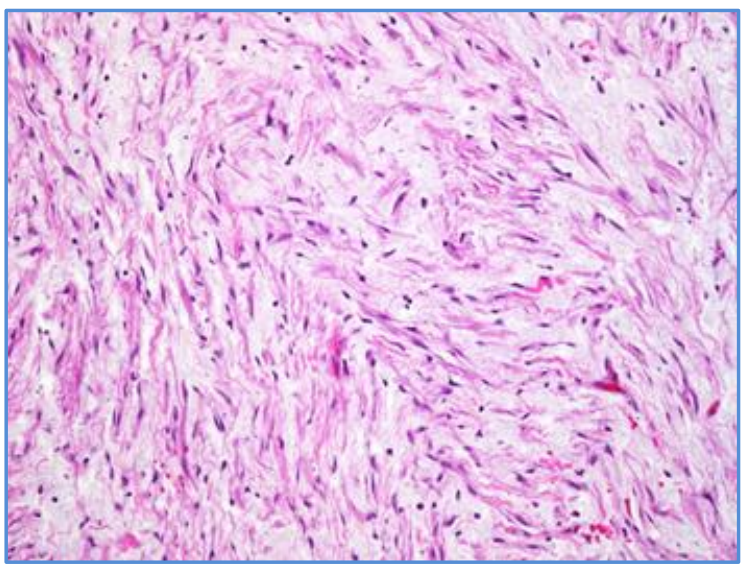

Fig. 5: Histopathology showing features of plexiform neurofibroma 


\section{CASE REPORT}

There was no associated with peripheral lymphadenopathy and no neuro-vascular deficit.

Investigations done showed normal blood count but with severe anemia of haemoglobin $4.5 \mathrm{~g} / \mathrm{dl}$. Plain radiograph of femur showed normal bones. Chest radiograph is normal. Arterial Doppler of left lower limb is normal. Aspirate cytology was negative for malignancy. Anemia of the patient corrected and posted for surgery.

Patient was operated under spinal anaesthesia incision is fashioned around the base of the pedunculated tumor and dissected with careful ligation of feeding vessels. Whole mass is delivered and incision closed by primary closure in 2 layers with a subcutaneous suction drain.

Specimen weighed $27 \mathrm{kgs}$ and measured $70 \times 40 \times 30 \mathrm{~cm}$. Grossly there was diffuse presence of a myxoid-like white tan tissue infiltrating into the surrounding fat. Histopahological examination revealed a plexiform neurofibroma with no evidence of malignancy.

Post-operatively patient is relieved of the discomfort symptoms due to the presence of mass. Patient limb was immobilized for heeling. Drain removed on day 2. Patient mobilized on day 4 and patient doing daily routine without any discomfort.

DISCUSSION: Neurofibromas are, first described by Smith in 1849 and Von Recklinghausen in 1882 later, benign tumors arising from nerve sheath ${ }^{6}$. PNs are said to be pathognomonic for neurofibromatosis. ${ }^{7}$ The growth patterns of PNs are classified into superficial, invasive, and displacing types. Superficial type arise from subcutaneous or cutaneous nerves from its supporting elements. Invasive type infiltrate multiple tissue planes and difficult to resect without functional disturbance ${ }^{4}$. Rapid growth of PN and onset of clinical neurological deficits indicates malignant transition and need immediate evaluation. ${ }^{5}$

PNs have $5-10 \%$ risk of malignant transformation. ${ }^{3}$ Some suggest early resection of smaller tumors may minimize the extent of involvement locally. ${ }^{8}$ But currently options are limited to surgical intervention and there is debate regarding timing of operation and extent of resection ${ }^{4}$. The clinical presentation of PN in an individual have a significant impact on the patient's quality of life because of the emotional burden and social stigma. National Institute of Health Consensus development conference on neurofibromatosis (NHIS, CDC 1988) 3 gives clinical criteria for the diagnosis ofNF1.

This includes two or more of the following:

a. 6 or more café-au-lait spots of $>15 \mathrm{~mm}$ diameter in post pubertal persons (or $<5 \mathrm{~mm}$ in prepuberty).

b. At least 2 neurofibromas of any type or 1 plexiform neurofibroma.

c. Freckling in the axilla or groin.

d. Optic glioma.

e. At least 2 lisch nodules.

f. A distinct bony lesion including sphenoid wing dysplasia or thinning of long bone cortex.

g. A first degree relative with NF-1.

Histologically, NFs show elongated interlacing bundles of cells and lack epithelial elements and demonstrate S-100 positivity ${ }^{6}$. There is a significant discrepancy in the size of the tumor to be described as giant neurofibroma. Taking in consideration the published cases of large neurofibromas, the word "giant neurofibroma" is used for those weighing $20 \%$ or more of patient's total body weight. ${ }^{1}$ 
Surgical treatment offers the desired optimal treatment and recurrence is rare but dangerous bleeding may complicate the procedure. With proper managing strategies subtotal or total resection without functional impairment is possible. Some may require complex intraoperative management strategies like sequential preoperative embolization etc. ${ }^{1}$ In this case careful suture ligation done for the feeding blood vessels avoiding the friable parts.

CONCLUSION: Management of the giant neurofibroma is a surgical challenge and rewarding in relieving patient discomfort arising from the presence of huge mass that will interfere in performing daily routine work. Resection also needed for the possibility of malignancy. Patient should be improved in term of nutrition and also work up should done which include $\mathrm{x}$ ray to rule out bony involvement and Doppler to rule vessel abnormalities that may cause limb ischaemia if inadvertently ligated. Because of the vascularity and friability of the vasculature sometimes complex intraoperative management strategies are required.

\section{REFERENCES:}

1. Roberto Vélez, Sergi Barrera-Ochoa, David Barastegui, Mercedes Pérez-Lafuente, CleofeRomagosa, and Manuel Pérez, "Multidisciplinary Management of a Giant Plexiform Neurofibroma by Double Sequential Preoperative Embolization and Surgical Resection", Hindawi Publishing Corporation Case Reports in Neurological Medicine Volume 2013, Article ID 987623, 8 pages.

2. R. E. Ferner and D. H. Gutmann, "International consensus statement on malignant peripheral nerve sheath tumors in neurofibromatosis," Cancer Research, vol. 62, no. 5, pp. 1573-1577, 2002.

3. Victor Nwagbara, Maurice Asuquo, Samuel Akpan, Dianabasi Eduwem, Ayodele Omotoso and Theophilus Ugbem, "Giant Solitary Intramuscular Cystic Plexiform Neurofibroma of the Thigh: A Case Report and Literature Review", International Journal of Case Reports in Medicine http://www.ibimapublishing.com/journals/IJCRM/ijcrm.html Vol. 2013 (2013), Article ID 436550, 6 pages DOI: 10.5171/2013.436550.

4. Y. Ji, B. Xu, X. Wang et al., "Surgical treatment of giant plexiformneurofibroma associated with pectusexcavatum,"Journal of Cardiothoracic Surgery, vol. 6, p. 119, 2011.

5. D. H. Gutmann, A. Aylsworth, J. C. Carey et al., "The diagnostic evaluation and multidisciplinary management of neurofibromatosis and neurofibromatosis 2, " Journal of the American Medical Association, vol. 278, no. 1, pp. 51-57, 1997.

6. Sherman JE, Smith JW: Neurofibromas of the breast and nipple areolar area. Ann PlastSurg 1981, 7:302307.

7. Le LQ, Parada LF: Tumor microenvironment and neurofibromatosis type I: connecting the GAPs. Oncogene 2007, 26(32):4609-4616.

8. Nguyen R, Kluwe L, Fuensterer C, Kentsch M, Friedrich RE, Mautner VF: Plexiform Neurofibromas in Children with Neurofibromatosis Type 1: Frequency and Associated Clinical Deficits. J. Pediatr 2011. 


\section{CASE REPORT}

\section{AUTHORS: \\ 1. P. Ravi Kumar Reddy \\ 2. Rajashekar S. B. \\ 3. Somashekhar Samagandi}

\section{PARTICULARS OF CONTRIBUTORS:}

1. Assistant Professor, Department of Surgery, VIMS, Bellary.

2. Assistant Professor, Department of Surgery, VIMS, Bellary.

3. Associate Professor, Department of Plastic Surgery, VIMS, Bellary.

FINANCIAL OR OTHER

COMPETING INTERESTS: None

\section{NAME ADDRESS EMAIL ID OF THE} CORRESPONDING AUTHOR:

Dr. P. Ravi Kumar Reddy, Department of Surgery,

VIMS, Bellary.

E-mail: drravireddy@gmail.com

Date of Submission: 18/02/2015.

Date of Peer Review: 19/02/2015.

Date of Acceptance: 20/02/2015.

Date of Publishing: 23/02/2015. 